\title{
- Childhood Somatotroph pituitary adenomas due to Aryl hydrocarbon receptor interacting protein $(A I P)$ gene mutations
}

\section{E. Coxson ${ }^{1}$, J.S. Barton ${ }^{1}$, M. Dang ${ }^{2}$, M. Korbonits ${ }^{2}$ \& C.P. Burren ${ }^{1}$}

${ }^{1}$ Department of Paediatric Endocrinology, Bristol Royal Hospital for Children, University Hospitals Bristol NHS Foundation Trust, Bristol, UK ${ }^{2}$ Department of Endocrinology, Barts and The London School of Medicine, London, UK.

Introduction: Two childhood cases of somatotroph pituitary adenomas caused by AIP gene mutations highlight the importance of screening for Familial Isolated Pituitary Adenoma (FIPA) genes in index cases and family members.

Case 1: 13.5 year old girl presented with 5 years growth acceleration and size 10 feet. No headaches or visual disturbance.

Examination: Acromegalic facies, large hands and feet. Height $177 \mathrm{~cm}$ $\left(>99.6^{\text {th }}\right.$ centile, SDS +2.8$)$. Mid parental centile $\approx 25^{\text {th }}$ centile.
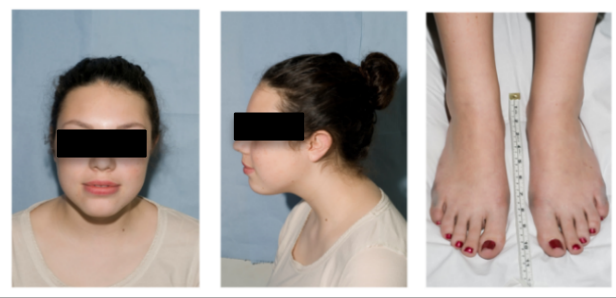

Biochemistry: OGTT showed elevated baseline GH with marked failure to supress and impaired glucose tolerance. IGF-1 208nmol/I (23-90). Pituitary function otherwise normal.

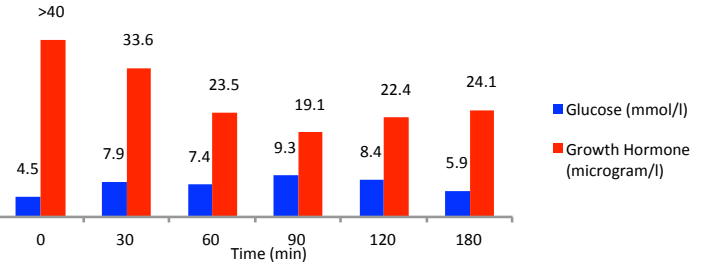

MRI: $18 \mathrm{~mm}$ pituitary mass with suprasellar extension.

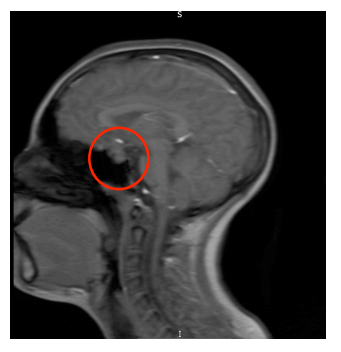

Histology: Pituitary adenoma (Fig1a) Immunohistochemistry shows adenoma cells strongly positive for $\mathrm{GH}$ but largely negative for ACTH, FSH, LH, TSH and prolactin (Fig1b). Overall appearances consistent with $\mathrm{GH}$ secreting adenoma.

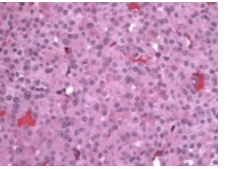

Fig $1 a$

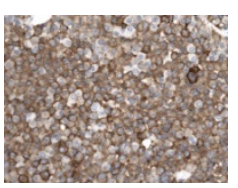

Fig $1 b$
Post surgical resection: Developed sphenoidal abscess resulting in permanent left temporal upper quadrantinopia. Subsequently normalisation of IGF-1, growth and normal pituitary function

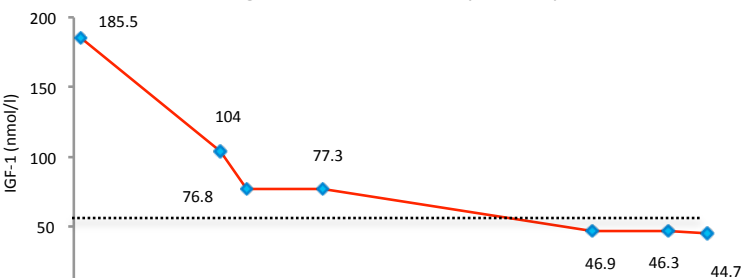

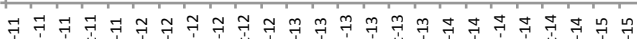

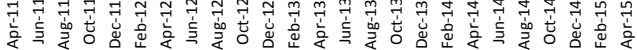

Genetics: A novel heterozygous frameshift mutation in AIP c. 376_377del; p.Q126fs was identified. Her mother was an asymptomatic carrier (IGF-1 18.8nmol/I [7.0-25.9], prolactin 248mIU/I [<700], supressed GH on OGTT [nadir $0.2 \mathrm{mcg} / \mathrm{l}]$ ). Her siblings tested negative and mother's family is undergoing genetic testing.
Case 2: 10 year old boy presented with daily headaches and sudden onset blurred vision with recent growth acceleration and increase in shoe size.

Examination: Slight coarsening of facies, blurred infero-temporal visual fields. Height SDS +3.05.
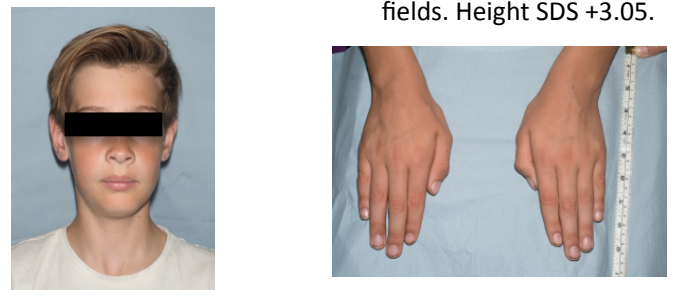

MRI: Pituitary adenoma with suprasellar extension and left optic nerve compression.

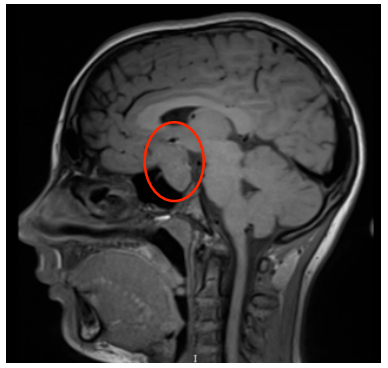

Initial Management: Urgent transsphenoidal resection of tumour.

Histology: Pituitary adenoma immuno-positive for $\mathrm{GH}$, but negative for other pituitary hormones.

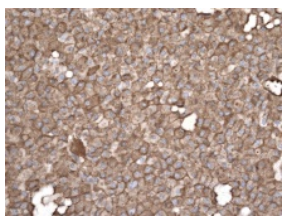

Post-operative course: IGF-1 remained elevated (91.4nmol/I [9.8-61.0]) 6 weeks post resection. No preoperative sample for comparison due to insufficient sample being sent.

OGTT 6 weeks post-op: Ongoing GH hypersecretion.

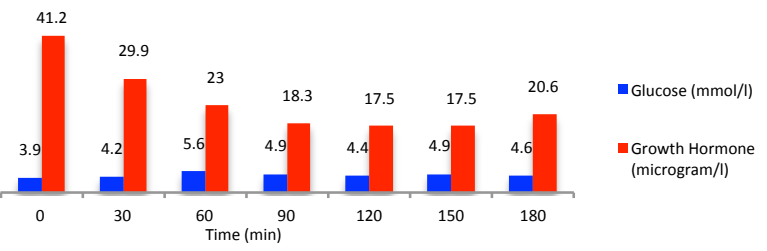

Medical Management: Octreotide commenced as shown but IGF-1 remained elevated. Patients with AIP mutations are known to respond poorly to somatostatin analogue therapy. Further surgical clearance undertaken. Further therapy options include GH receptor antagonist or pasireotide treatment.

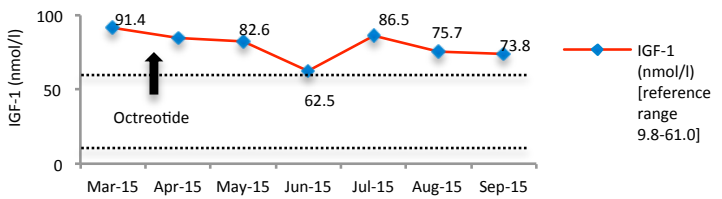

Genetics: A previously described missense AIP mutation c.811C >T;p.R271W was identified, which was shown to disrupt the function of the protein (Leontiou, JCEM, 2008). Mother asymptomatic carrier referred to adult endocrinology for assessment. Family testing important in both cases as AIP mutations show autosomal dominant inheritance with $23 \%$ penetrance. 